\title{
Impact of indiscriminate use of insecticide on environmental pollution
}

D. DEY

Department of Agricultural Entomology, College of Agriculture, Orissa University of Agriculture and Technology, BHUBANESWAR (ODISHA) INDIA

\section{ARITCLE INFO}

Received : 16.11 .2015

Accepted : 16.03 .2016

\section{KEY WORDS :}

Impact of indiscriminate, Use of insecticide, Environment pollution

Corresponding author:

Email: dipankard799@gmail.com

\begin{abstract}
Insecticide use is an important and integral component of crop production system. Insecticide use increased substantially over the years. Insecticide consumption increased by 2158.6 per cent in 2004 over 1982, but now there is declining trend in their use. Indiscriminate use of insecticides also lead to several diseases in human health. Concentration of insecticide in surface and ground water is also a major factor for environmental pollution. Insecticide like Diazinon shows the maximum concentration in surface and ground water. Therefore, the concentration of Diazinon should not be more than the recommended limits i.e. $0.003 \mu \mathrm{g} / \mathrm{l}$ to protect the fresh water aquatic life and also eliminate the lethal effects of insecticide residues in ground water. The status of the insecticide residue in lake water i.e. the areas that were not involved in vegetable or horticultural farming is highest in chlorpyriphos ethyl (which was above WHO limit) while the residual levels of endosulfan sulphate and endosulfan ether found in agricultural soil were higher than those of alpha and beta endosulfan, which indicates that degradation reactions take place mainly in agricultural soil.
\end{abstract}

How to view point the article : Dey, D. (2016). Impact of indiscriminate use of insecticide on environmental pollution. Internat. J. Plant Protec., 9(1) : 264-267. 